\title{
Comparative analysis of the biomechanical behavior of two different design metaphyseal-fitting short stems using digital image correlation
}

\author{
I. Tatani ${ }^{1 *} \mathbb{D}$, P. Megas ${ }^{1}$, A. Panagopoulos ${ }^{1}$, I. Diamantakos ${ }^{2}$, Ph. Nanopoulos ${ }^{3}$ and Sp. Pantelakis ${ }^{2}$
}

*Correspondence:

irinitatani@gmail.com

${ }^{1}$ Orthopaedic Department, University Hospital of Patras, Papanikolaou 1, Rio-Patra, 26504 Patras, Greece

Full list of author information is available at the end of the article

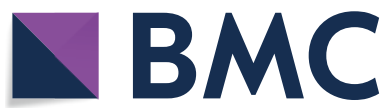

(0) The Author(s) 2020. This article is licensed under a Creative Commons Attribution 4.0 International License, which permits use, sharing, adaptation, distribution and reproduction in any medium or format, as long as you give appropriate credit to the original author(s) and the source, provide a link to the Creative Commons licence, and indicate if changes were made. The images or other third party material in this article are included in the article's Creative Commons licence, unless indicated otherwise in a credit line to the material. If material is not included in the article's Creative Commons licence and your intended use is not permitted by statutory regulation or exceeds the permitted use, you will need to obtain permission directly from the copyright holder. To view a copy of this licence, visit http://creativecommons.org/ licenses/by/4.0/. The Creative Commons Public Domain Dedication waiver (http://creativecommons.org/publicdomain/zero/1.0/) applies to the data made available in this article, unless otherwise stated in a credit line to the data. 
Keywords: Total hip arthroplasty, Short stem, Digital image correlation, Finite element analysis, Experimental validation

\section{Background}

Total hip arthroplasty (THA) is arguably considered a reliable procedure to provide pain relief, restore function and improve quality of life in patients with advanced hip osteoarthritis [1-9]. While in the past, the procedure was mainly reserved for fragile elderly patients, the success of the procedure has expanded its indications to relatively younger and more active patients [10], whose sole debilitating limitation in daily living is the affected hip joint. In order to cope with this new surge of popularity of THA, several efforts have been made to accelerate the rehabilitation process, maximize the longevity of the implants and eliminate morbidity related to a future revision procedure. Recent innovations are therefore mainly aimed towards reducing soft tissue damage and preserving native bone without compromising implant stability [11].

The reduction of strain in the bone caused by an adjacent load-carrying implant can lead to a subsequent reduction in surrounding bone density, causing the well-known stress-shielding phenomenon $[12,13]$. There are conflicting data in the literature concerning the clinical significance of stress-shielding effect, with some authors advocating that the adverse implant-induced bone adaptation can compromise the longevity of cementless THA [14-16]. According to other studies, periprosthetic bone resorption commonly observed around cementless implants has not yet correlated with any increased risk of aseptic loosening or periprosthetic fracture [17-20]. Though it is not proven that stress-shielding effect is directly related to the survival of implants, an excessive bone loss around a primary prosthesis can complicate a potential revision procedure. Consequently, the preservation of proximal periprosthetic bone is considered a vitally important principle in THA, and different stem designs have been launched in an effort to preserve a physiological load transfer to the femur, thus eliminating stressshielding effect.

A heterogeneous group of conservative femoral prostheses, called short stems, have emerged as an alternative to conventional stems, with differences in terms of design, biomechanics and method of fixation [21, 22]. Ideally, a short-stem implant should provide rigid primary fixation, extensive metaphyseal bone-implant contact for sufficient osseointegration and a more physiological load transfer reproducing a biomechanical behavior more similar to the physiological bone. However, the benefits of short femoral stems remain hypothetical and there is not a clear understanding of the influence of short-stem designs on bone biomechanics [23, 24].

Numerous biomechanical studies have been performed comparing different femoral stem design features in an attempt to find a way to eliminate the stress-shielding effect of the implanted femurs. Most studies indicate that the stiffer the implant, the more pronounced the stress shielding [25-28]. The following solutions have been proposed in an effort to reduce stems' stiffness, including an optimum selection of constitutive materials [29-31], internal structure, geometry and shape [32-38].

This study combines experiments and numerical simulations to investigate the biomechanical properties of two different design short stems, the TRI-LOCK Bone Preservation Stem (DePuy Orthopaedics Inc. Warsaw, USA) (Fig. 1a) and the Minima S Femoral 

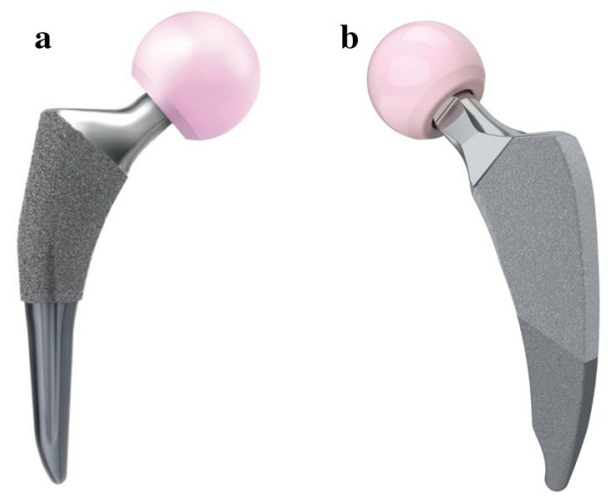

Fig. 1 Femoral stems. a Trilock BPS stem. b Minima S stem

Stem (Lima corporate Villanova di San Daniele, Italy) (Fig. 1b). According to the detailed classification system of short stems proposed by Gómez-García et al. [39] in 2016, the Tri-Lock Bone Preservation Stem (Tri-Lock BPS) and Minima S stems are classified as type $\mathrm{C}$, meaning that they occupy the cervico-metaphyseal-diaphyseal area. In our point of view, an important issue that should be addressed is whether all variations of currently available metaphyseal-fitting short stems could offer similar load transfer characteristics before making any generalized recommendation for their overall use. The study's hypothesis was that even these subtle variations, regarding stem length and geometric design between these two stems, which are classified within the same subgroup, may create different strain distribution patterns and thus dissimilar biomechanical behaviors. For this purpose, the transmission of forces as measured by cortical surface strain distribution in the proximal femur was evaluated using Digital Image Correlation (DIC), first on the non-implanted femur and then on the implanted femurs with the TRI-LOCK BPS and Minima $S$ femoral stems in respect. The strain patterns of the non-implanted femur served as the control group. The DIC full-field strain patterns in intact and implanted composite femurs were compared and also the corresponding numerical models were developed and evaluated for their validity against mechanical tests.

\section{Results}

Comparison of DIC-measured strains between intact and implanted femurs

Before comparing DIC-measured strains between intact and implanted femurs, DIC strains of the several tests concerning the same case and loading level (1000 N was considered) were compared via linear correlation analyses. Slopes were close to 1 and thus the fields obtained from different repetitions showed a good agreement. Figure 2 depicts the typical numerical and experimental fields for the intact and implanted bones in each of the two fields of view. In the DIC analysis, the non-implanted femoral bone, serving as a reference model of healthy bone exhibited higher strain response to loading in the proximal medial area than any of the implanted femurs. The quantitative full-field strain analysis demonstrates a clear trend of increased strain along the longitudinal axis of the femur from proximal to distal at the medial side. In the proximal medial aspects of the femur (zones of interest M1, M2) there was a statistically significant decrease in the mean principal compressive strain of implanted bones compared to that of the intact 


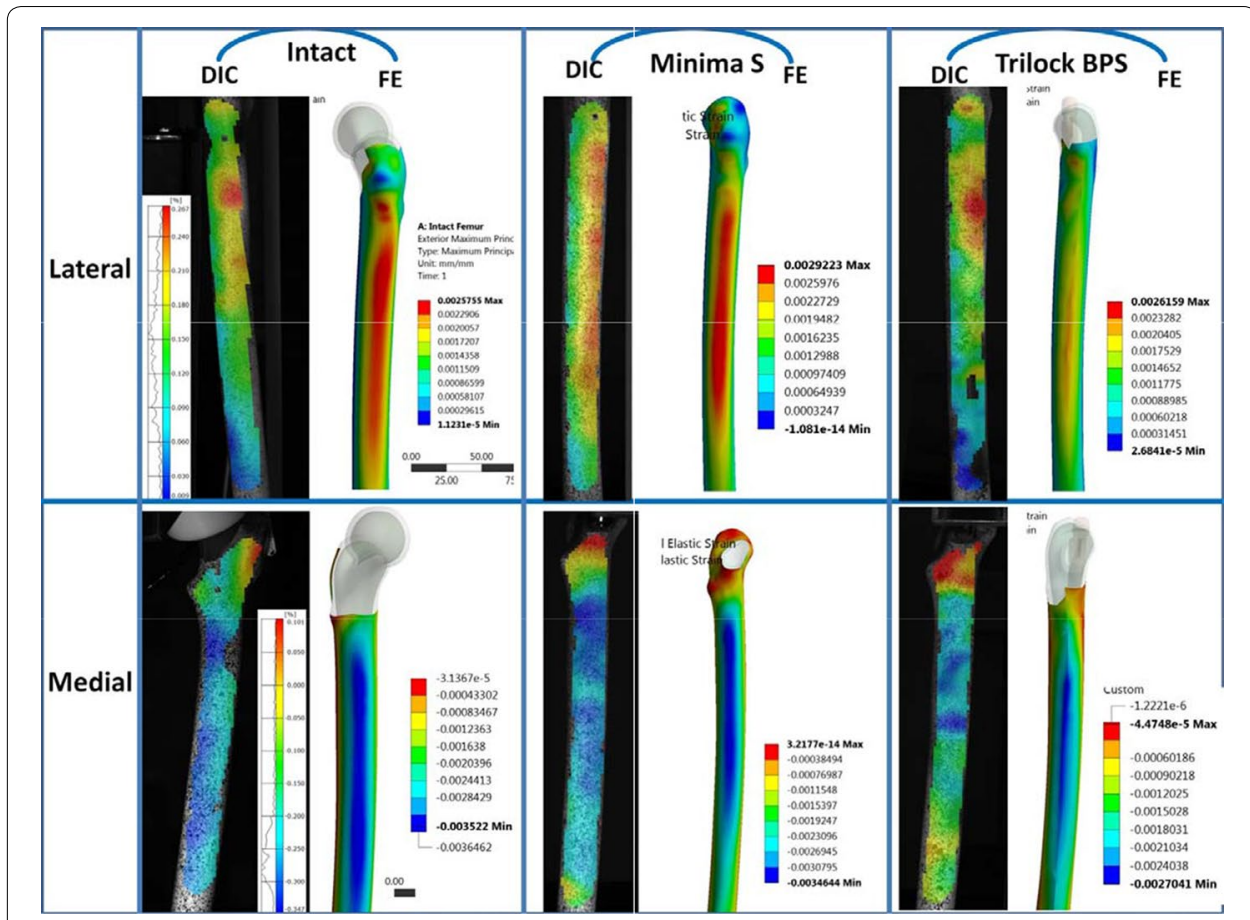

Fig. 2 DIC-measured and FE-predicted strains for each specimen in each of the two fields of view

femur. The percentage variance in the mean compressive strain at these proximal medial zones was greater for the Trilock BPS compared to the Minima S. At zones M3 to M7, implanted specimens exhibited a strain response most closely matching that of the intact femur. At these distal zones, the percentage variance of strain was less pronounced in both groups of implanted femurs.

At the L1 zone of interest, the attachment of the metallic blade to the greater trochanter prevented DIC equipment to visualize this zone, and hence the measured strain data are lacking from this part of the bone. On the lateral aspect of the femur a decrease in principal tensile strains was observed in the implanted femurs at almost all measurement zones compared to the intact bone. The decrease in strain response was more pronounced for the Trilock BPS implanted specimens and significant differences were observed compared to the Minima $\mathrm{S}$ at almost each measurement zone. Strain response at each zone of interest along the medial and lateral femoral cortex is presented in Fig. 3, with statistical analysis presented in Table 1.

\section{FE model validation}

The obtained best-fitting polynomial curves of the experimental and calculated strain data relative to the long axis of the bone are presented in Fig. 4a, c for the medial and the lateral side, respectively. The validation of the numerical models was conducted via linear correlation analyses of the measured and calculated principal strains for each construct (Intact Femur, Minima S and Trilock BPS implanted bones) in each field of view. More specifically, FE simulation results and experimental measurements concerning minimal strains at the medial path of the bone were compared for the intact, Minima 
S and Trilock BPS implanted bones, respectively (Fig. 4b). Similarly, analytically and experimentally derived maximum strains at the lateral path of the bone were compared for the same three cases as above (Fig. $4 \mathrm{~d}$ ). The numerical model validation relies on the reasonable agreement observed between the numerical and experimental data in the majority of cases with the exception of the Trilock BPS implanted femur in the lateral surface (slope $=0.611, R^{2}=0.718$ ).

\section{Discussion}

This study was designed to investigate the biomechanical properties of two different design short stems, based on biomechanical testing and finite element models. These two methods should be combined to yield more precise measurements, as recommended by previous studies focusing on the evaluation of strain patterns induced after the implantation of a hip prosthesis [40, 41].

The DIC technique has been introduced into the field of biomechanics for accurate determination of surface strain in inhomogeneous, anisotropic, non-linear materials such as bone. The strain distribution patterns induced by different materials have been studied previously in the laboratory setting using strain gauge analysis [28, 42-45], photoelastic coating techniques [46, 47] and finite element analysis [48-50]. Traditionally, strain gauges have been considered the 'gold standard' in the experimental testing for evaluation of the biomechanical behavior of bone in vitro since their introduction in the late 1950s [51]. Although they are known to be reliable and despite their widespread use, strain gauges require surface preparation and provide strain results only at the restricted area of application. This lack of full-field strain data is considered to be a limitation of the technique. Digital image correlation is an optical full-field technique that allows noncontact, three-dimensional deformation measurements of objects subjected to external loads. To date, DIC has been used in many applications in biomechanics, such as a measurement tool of strains on bone surface with or without validation of finite element corresponding models [24, 31, 52-59] and also to evaluate relative micromotion between the implant and the surrounding bone $[24,60]$. In this study, we employed the three-dimensional DIC measurement technique to find the differences in strain patterns generated in composite femurs implanted with two different design femoral prostheses. The results showed that the DIC technique captured the strain on the bone surface well, providing full-field plots for each case, as opposed to application point results which would have been achieved using strain gauges.

The clear distal load transfer after the implantation of both short stems demonstrated in this study is congruent with previous studies, which have found a similar distally shifting load distribution pattern as a result of implant insertion [24, 61, 62]. Despite the fact that short-stem femoral implants have displayed a better biomechanical behavior preserving a strain distribution closer to the intact bone according to previous studies [24, $28,42,43,63-65]$, the implantation of a stiffer material absorbs the load and transfers it distally, leaving the proximal region of the calcar somewhat stress-shielded. The data presented here demonstrate that strain shielding and proximal unloading of the femur occurred even when using short-stem implants. Although there is a lack of evidence that stress-shielding effect could directly influence the clinical results, it is of predominate 


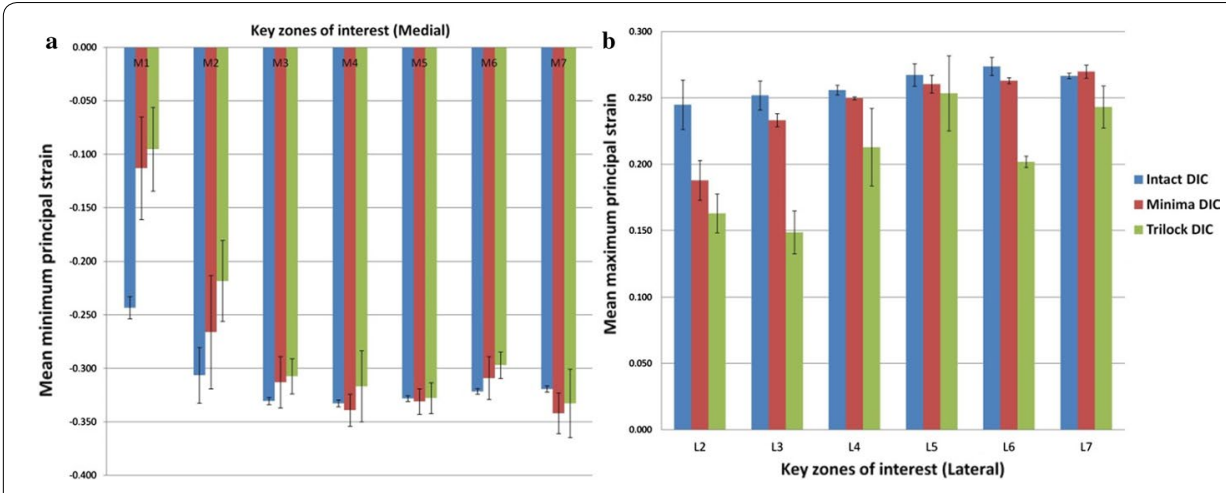

Fig. 3 DIC-measured strain response to single-leg stance loading in a medial and $\mathbf{b}$ lateral measurement regions

concern that a resorption of proximal femoral bone stock may negatively affect the stability and long-term survival of femoral implants $[28,66,67]$.

The results of the current study have potential clinical implications. While strain distribution patterns after the implantation of femoral implants in total hip arthroplasty have been previously investigated, this study determined quantitatively the specific strain data derived by two short femoral stems, which belong to the same category of cervico-metaphyseal-diaphyseal short stems. It seems that, even these subtle variations regarding stem length and geometric design are sufficient to produce significant strain changes. Although the clinical implication of the aforementioned differences in biomechanical behavior cannot be predicted, the clinicians must be really hesitant before making general recommendations about the clinical results of short femoral implants, even if they belong to the same category. Taking into consideration that the reduced strain in a region of bone is the definition of stress shielding, the patterns of strain distribution derived after the implantation of these stems could be correlated with the clinical results of future in vivo studies focusing on the bone remodeling response surrounding these implants.

Quantitatively, full-field strain distributions were in good agreement to the FEpredicted strain patterns in the majority of cases. Although a reduced correlation was observed for the Trilock BPS implanted femur in the lateral surface, the discrepancies could be explained by the fact that high spread values were obtained in this case.

This study, however, has certain limitations. At first, composite femoral bones were chosen instead of cadaveric human specimens. We acknowledge that the strain patterns induced after mechanical testing of these specimens are not equivalent to in vitro cadaveric models or in vivo clinical conditions. However, mechanical testing on synthetic femurs is considered a valid method of studying the biomechanical behavior of implanted femurs $[68,69]$. According to previous studies, composite femurs have been independently tested and shown a biomechanical behavior similar to that of human cadaveric specimens during loading [68, 70,71]. The composite bones present a lot of advantages compared to cadaveric specimens, including minimal inter-specimen variability, consistent material properties, high availability and low cost. Additionally, composite bones are independent from parameters that can substantially alter their properties, such as storage method, air temperature and humidity and time from harvest 
Table 1 Percentage strain for each prosthesis compared to the control femur and strain comparison for each zone of interest, $p$-values

\begin{tabular}{|c|c|c|c|c|c|}
\hline \multirow{2}{*}{$\begin{array}{l}\text { Key zone } \\
\text { of interest }\end{array}$} & \multicolumn{2}{|c|}{ Implanted Minima S femoral stem } & \multicolumn{2}{|c|}{ Implanted Trilock BPS femoral stem } & \multirow{2}{*}{$\begin{array}{l}\text { Minima S } \\
\text { to Trilock BPS } \\
\text { ( } p \text {-value) }\end{array}$} \\
\hline & $\begin{array}{l}\text { Percentage strain } \\
\text { against controls } \\
(\%)\end{array}$ & $\begin{array}{l}\text { Mann- } \\
\text { Whitney test } \\
\text { against controls } \\
\text { (p-value) }\end{array}$ & $\begin{array}{l}\text { Percentage strain } \\
\text { against controls } \\
(\%)\end{array}$ & $\begin{array}{l}\text { Mann- } \\
\text { Whitney test } \\
\text { against controls } \\
\text { (p-value) }\end{array}$ & \\
\hline \multicolumn{6}{|l|}{ Medial side } \\
\hline M1 & 68.7 & 0.001 & 57.1 & 0.000 & 0.029 \\
\hline M2 & 84.1 & 0.005 & 69.2 & $<0.0001$ & $<0.0001$ \\
\hline M3 & 101.0 & 0.029 & 89.4 & $<0.0001$ & $<0.0001$ \\
\hline M4 & 102.5 & $0.529^{a}$ & 97.8 & $0.139^{\mathrm{a}}$ & $<0.0001$ \\
\hline M5 & 99.1 & $0.459^{\mathrm{a}}$ & 98.2 & $0.752^{\mathrm{a}}$ & $0.153^{\mathrm{a}}$ \\
\hline M6 & 98.3 & $0.13^{\mathrm{a}}$ & 96.7 & $<0.0001$ & 0.000 \\
\hline M7 & 106.1 & 0.001 & 101.6 & $0.556^{\mathrm{a}}$ & 0.003 \\
\hline \multicolumn{6}{|l|}{ Lateral side } \\
\hline $\mathrm{L} 2$ & 87.5 & $<0.0001$ & 79.2 & $<0.0001$ & $0.935^{\mathrm{a}}$ \\
\hline L3 & 89.1 & $<0.0001$ & 57.8 & $<0.0001$ & $<0.0001$ \\
\hline$\llcorner 4$ & 98.2 & 0.000 & 82.2 & $<0.0001$ & $<0.0001$ \\
\hline L5 & 98.1 & 0.043 & 92.6 & 0.004 & 0.002 \\
\hline L6 & 95.4 & 0.000 & 81.2 & $<0.0001$ & $<0.0001$ \\
\hline L7 & 100.3 & $0.131^{a}$ & 87.7 & $<0.0001$ & 0.006 \\
\hline
\end{tabular}

a Not significant

[70]. In this study, where a direct comparison between two implant systems was made, the proven low inter-specimen variability of composite femurs can provide more consistent results, eliminating confounding factors.

In the presented experimental testing setup and in accordance with previous reports $[26,31,64,72]$ the physiological load applied to the femoral bone was reduced to a simpler configuration, where only the abductors were included. Despite the complexity of the biomechanics involving the hip, recent in vitro biomechanical studies evaluating femoral prostheses tend to be as simple as possible, not fully accounting for the numerous soft-tissue interactions which actively contribute to hip joint stability and femoral loading characteristics. Furthermore, abductor muscle forces have been demonstrated to exert the greatest impact on strain patterns in the proximal femur and thus the other soft tissues could be ignored in a first approximation [73].

In this study, the phase of gait to be simulated was chosen to be the single-leg stance that represents a simplified model of the natural physiological loading state. The fact is that there is no general agreement about the optimal loading condition for the evaluation of changes in strain patterns on the proximal femur [74]. This simplified loading phase already described in the literature [75] combines simultaneous compression and bending forces and results in a more physiological loading condition than isolated compression or bending loading.

Experimental studies evaluating strain patterns in femoral bones after insertion of femoral prostheses are valuable in the assessment of their biomechanical behavior. Nevertheless, we acknowledge that neither experimental studies nor numerical analyses can uncritically predict the clinical performance of an implanted material. We are also aware that cortical strain measurement cannot directly reflect the in vivo performance because 


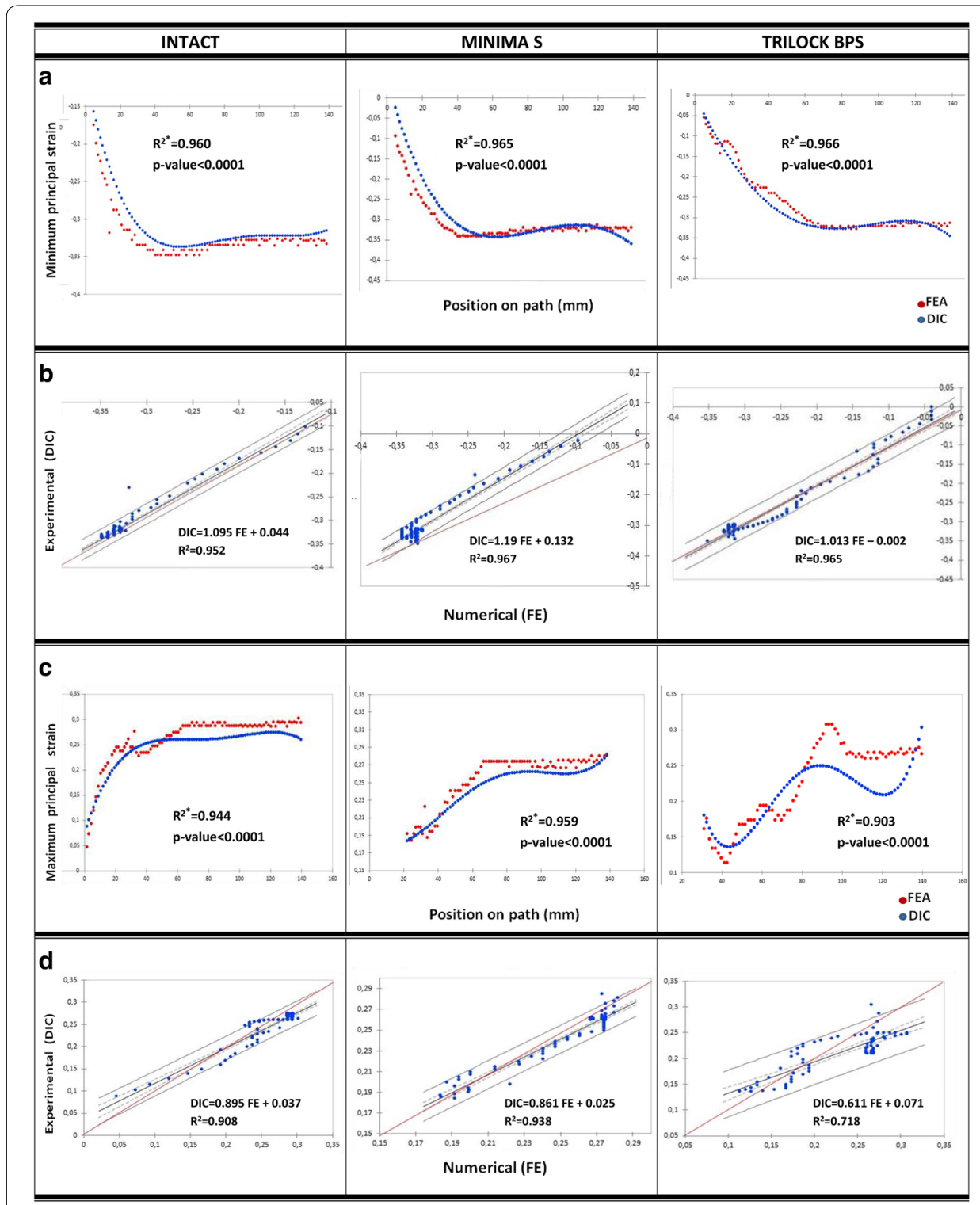

Fig. 4 Medial field of view. $\boldsymbol{a}$ Best-fitting polynomial curves of the FE-predicted and DIC-measured strain data relative to the long axis of the bone for the intact and implanted bones with Minima $S$ and Trilock BPS. $\mathbf{b}$ Linear regression analysis. Lateral field of view. c Best-fitting polynomial curves of the FE-predicted and DIC-measured strain data relative to the long axis of the bone for the intact and implanted bones with Minima S and Trilock BPS. $\mathbf{d}$ Linear regression analysis; $R^{2^{*}}$ : coefficient of determination in polynomial regression, $R^{2}$ : coefficient of determination in linear regression analyses

composite models represent a nonviable bone without the capacity to be remodeled. For this purpose, a simultaneous clinical study is already running, aiming to assess the remodeling process around these specific implants in vivo, by means of a detailed radiological analysis [76]. Nevertheless, this testing setup provides useful data for the biomechanical behavior of these implants, which in turn may indicate their clinical performance in the first postoperative period.

Concerning finite element models, the usual limitations are present. The material properties of bone are orthotropic rather than isotropic, as specified in this finite 
element model. Nevertheless, the developed numerical model could be considered valid and reliable as provided by the reasonable agreement observed between the numerical and experimental data.

\section{Conclusions}

This study provides evidence to support the use of DIC technique as a preclinical evaluation tool of the biomechanical behavior induced by different implants. The results of this study also support DIC's potential for biomechanical FE model validation. Design differences between Trilock BPS and Minima S conditioned different strain pattern distributions and thus our primary hypothesis that design-specific variations in these specific short stems are sufficient to produce dissimilar strain patterns was confirmed. An obvious decrease of strain in the medial proximal aspect of the femur was noted for both stems, demonstrating that proximal unloading of the femur could not be avoided. At the lateral surface, both implanted specimens exhibited a persistent decrease in principal tensile strains at almost all measurement zones compared to the intact bone. Nevertheless, alteration in strain patterns induced after the implantation of the Trilock BPS stem was greater compared to the Minima S stem at all regions of interest on the lateral cortex. Being aware that the findings of this study could not be used uncritically to predict the in vivo performance of these femoral implants, our ongoing randomized, clinical study aims to add information regarding the clinical effects of the differences observed in femoral strain patterns between the two prostheses.

\section{Methods}

\section{Experimental study}

The experimental work was undertaken in the Laboratory of Technology and Strength of Materials at the Department of Mechanical Engineering and Aeronautics. Short stems with predominantly metaphyseal fixation, such as the TRI-LOCK Bone Preservation Stem and the Minima S Femoral Stem were chosen for the purpose of the study.

Tri-Lock BPS is a short tapered-wedge stem. It is made of titanium alloy with a highly porous pure titanium ("GRIPTION ${ }^{\circledR ”}$ ) coating on the proximal $50 \%$ portion that is engineered to provide an enhanced coefficient of friction when compared to POROCOAT ${ }^{\circledR}$ porous coating, which is on the original Tri-lock stem. Compared to its clinically successful predecessor, the Tri-Lock stem, the BPS stem is shorter, has a narrower distal segment, and features a curved distal tip. It is available in 13 stem sizes (size $0-12 /$ length 95-119 mm) with standard and high offset options for all stem sizes. The high offset option provides direct lateralization, increasing offset without affecting either the leg length or the neck-shaft angle.

Minima S Monolithic Femoral Stem is a short, curved, four tapered proximally porouscoated titanium femoral stem with 12 stem sizes (size 1-12/length $82-118 \mathrm{~mm}$ ) in standard and lateralized configuration available. The standard versions have a neckshaft angle of $134^{\circ}$, while the lateralizing versions have a neck-shaft angle of $131^{\circ}$.

Although both stems belong to the same short stem family, Minima S stem is even shorter compared to Trilock BPS, has an anatomic shape following the natural curvature of the medial calcar, preventing breach of the greater trochanter and a medially sidecutted tip to reduce the risk of contact with the cortical medial wall. 
A total of seven fourth-generation medium composite femurs from Sawbones Europe (Malmö, Sweden) with identical design and material properties were used, as previous described in similar biomechanical studies [66, 70, 77-81]. For each prosthesis, three different composite femoral bones were randomly allocated to receive either the TriLock BPS or the Minima S Femoral Stem. The intact femur was used as a bench top experimental estimate of the non-implanted state.

To provide a proper primary fixation and restore the hip biomechanics as accurately as possible, the choice of the correct implant size and offset is imperative. Changes of the neck offset after the implantation of the femoral stem relative to the intact reference bone could have an influence to the moment arm of the force applied on the femoral head, altering the strain distribution on the proximal femur. To account for these critical parameters, implants' templates provided by the manufacturers (DePuy Orthopaedics Inc. Warsaw, USA and Lima corporate Villanova di San Daniele, Italy) were superimposed on calibrated radiographs of the intact femurs. Reference points were the femoral axis and the center of the femoral head, marked by means of a best-fitting circle to the intact femoral head. The implant size was determined as a size 4 high offset with a -2 , $28 \mathrm{~mm}$ diameter femoral head for the Trilock BPS stem. The size of 4 high offset with a $-4,28 \mathrm{~mm}$ diameter femoral head was chosen for the Minima $\mathrm{S}$ femoral stem.

For the experimental preparation, the distal condyles of the intact femur were embedded into a steel cylinder using an ultra-low viscosity casting resin (SmoothCast Urethane Series 300 potting material, Smooth- On Inc, Easton, PA, USA). For a standardized embedding procedure, a custom alignment fixture was manufactured based on a previous reported femur-aligned reference system [82]. The embedding procedure was performed ensuring that the central axis of the femur through fossa piriformis coincided with the central axis of the cylinder and the posterior condylar surface was used for rotational alignment. For the correct positioning of the femur at the correct directions a system of arms, a laser level and a goniometer were used. Using the customized fixture, the femurs were positioned neutral on the sagittal plane and angled at $11^{\circ}$ of adduction in frontal plane, which corresponded to the physiological inclination during single-leg stance [83].

Six different composite femoral bones (three for each prosthesis) were prepared to accommodate the prostheses and all implantations were performed by the same investigator. Each prosthesis was implanted into the prepared femur with a tight fit, without macro-movement evident when a compressive force was applied. The accuracy of implantation of the femoral stems in the composite femurs in terms of correct implant size and positioning was verified using calibrated radiographs of both the intact and implanted femurs. The radiographs of the best-fitting template-matched radiographs of the intact femurs were superimposed on those of the implanted femurs (see Additional file 1). After the radiographic evaluation, the implanted femurs were fixed into the steel cylinder using the same embedding technique as described above. The proximal end of each femur was then prepared for DIC compatibility. For the creation of the speckle pattern, the surface of each specimen was initially covered using matte white color. To form a thin and uniform background, the femurs were sprayed from a distance of $50 \mathrm{~cm}$ and left to dry for $10 \mathrm{~min}$ before black speckles were applied. 
Then, the random speckle pattern was created using matte black commercial spray paint can. In the resulting speckle pattern, the speckle size was $0.7-1.0 \mathrm{~mm}$.

A custom-made mechanic jig was designed and manufactured according to the standardized protocol for testing conditions during functional validation of hip prostheses reported by Cristofolini and Viceconti [83] (Fig. 5). It consisted of a metal beam with an acetabular component properly attached to its undersurface, creating an articulation with the femoral head. The acetabular cup containing the femoral head had an inclination of $45^{\circ}$ and $0^{\circ}$ anteversion and its center was positioned $110 \mathrm{~mm}$ lateral to the load axis. The jig was supported on the femoral head through the acetabular cup and was attached medially to the load cell of the testing machine (Tinius Olsen electro-mechanical testing machine). The testing machine is computercontrolled and can apply tensile or compressive forces up to $5 \mathrm{kN}$. A system of cross rails were attached to the testing machine to guarantee that only a vertical force was applied to the cantilever device, avoiding undesired horizontal forces and moments. A system of rulers and goniometers allowed the position and direction of the forces to be controlled with an accuracy of $\pm 0.5 \mathrm{~mm}$ and $\pm 0.5^{\circ}$, respectively.

In the experimental fixture, a metallic blade was adhesively bonded at the lateral aspect of the greater trochanter, formed an angle of $40^{\circ}$ to the femoral diaphysis, which simulated the pelvis. The test fixture was designed to provide a compressive force to the femoral head through the acetabular cup and a tensile force simulating the contraction of the abductors to the greater trochanter. A bolt was utilized to control the force and a load cell was used to monitor the force exerted by the abductors under loading condition. For the geometry of the specific loading fixture, which is based on the study of Cristofolini [83], the contraction force had to be 1.62 times the vertical force. Thus, at every load level applied and due to the deformation of the femur, the bolt has been used to adjust the force exerted by the abductors to the desired level (from 0 to $1620 \mathrm{~N}$ ). The gait phase to be simulated was chosen to be the single-leg stance at the moment immediately after heal strike when the highest hip joint load acts $[84,85]$.

The non-implanted and implanted femurs were each placed into the custom-made jig, which was again mounted in the load cell of the testing machine. Loads were applied on the head of the intact composite femur and on the $28 \mathrm{~mm}$ metal head prostheses of the implanted bones through the acetabular cup. During the tests, the specimens were initially loaded with $100 \mathrm{~N}$ and the load was increased by increments of $100 \mathrm{~N}$ up to a total of $1000 \mathrm{~N}$. Each craniocaudal load was applied three times and the strain patterns were recorded at the maximum load level of each loading cycle.

Experimental analysis was based on 3-dimensional optical measuring system, the Aramis 5 M DIC system (GOM mbH, Braunschweig, Germany). DIC measurements were performed using two different cameras positions capturing opposite femoral surfaces, the lateral (tension) and the medial (compression) surface of the bone. 3D DIC system consisted of a stand that provided stability of the cameras, an image recording and power control unit and the data processing software. The cameras' setup used lenses with a focal length of $17 \mathrm{~mm}$. The cameras were positioned at a relative angle of $25^{\circ}$ and at a measuring distance of $875 \mathrm{~mm}$, which led to a resolution of the captured images of $2448 \times 2050$ pixels. The field of view using the specific setup was $400 \times 330 \mathrm{~mm}$. The 
facet parameters of the DIC software were adjusted (facet size $19 \times 19$ pixels, facet step $15 \times 15$ pixels) and a post-processed filter was applied to achieve reliable results, reducing the noise affecting strain measurements. Linear strain calculation has been applied with three adjacent points used in the strain calculation.

The non-implanted and implanted femurs were each placed into the testing machine and load up to $1000 \mathrm{~N}$ was applied according to the configuration described above. Images of speckle patterns were captured for the intact and implanted bones at unloaded and under $1000 \mathrm{~N}$ of compression loading conditions. The images obtained were analyzed using the Aramis code. The intact composite femur and each of the six prepared femurs were tested in this way. Three trials were repeated for each specimen (intact and 3 composite bones implanted with each prosthesis) in each field of view. DIC strains between the experiments for each construct were compared among themselves to assure repeatability. After repeatability was confirmed, DIC-measured strains from the last experimental repetition of each construct (intact, implanted bone with Trilock BPS and implanted bone with Minima S femoral stem) were used for the comparison of DICmeasured strains between intact and implanted femurs. The measured variables were the minimum principal strain on the medial femoral side and the maximum principal strain on the lateral cortex.

\section{Numerical analysis}

The geometrical model of the femoral Sawbone \#3908 (Femur-Medium left/reference part \#3403) was used in this study. It has been used as the base for the development of the finite element (FE) model. This geometrical model consists of three parts; the cortical bone and the proximal and distal cancellous cores. The average element size was set to $3 \mathrm{~mm}$ following a mesh-convergence study. The geometry of the two implants used in the present study has been acquired using the Hexagon Metrology Romer Absolute Arm equipped with an external high performance HP-L-20.8 laser scanner. The results of laser scanning were converted into 3-D solid models with the aid of a hybrid system using the CAD Software Catia V5 R 20. The geometry of the femur, after the neck osteotomy and before the implantation of each stem, has been created by the application of a Boolean operation, subtracting a cylindrical volume at the area of the femoral head. After modeling the femur, virtual implantation was performed positioning the implant in an orientation that replicated the tested specimen. Implant positioning in the model was based on the orthogonal photographs provided by the cameras during experimental setup and also the post-implantation antero-posterior and lateral radiographs. Parametric detailed 3D FE models of the femur and the implants have been developed using the commercially available ANSYS FE code. Tetrahedral elements have been used to develop the FE mesh, as they have been shown to discretize the femur and implants complicated geometries more efficiently than cubic hexahedral elements. Different linear material properties have been used to simulate the cortical and cancellous material of the bone. The femur consists of two different materials: short fiber-filled epoxy for the simulated cortical bone and solid rigid polyurethane foam for the simulated cancellous bone. Based on the data provided by the manufacturer, linear elastic, isotropic and homogeneous material properties were applied to the composite bone, with the simulated cancellous and cortical bone having Young's modulus $E=155 \mathrm{MPa}$ and $E=16.7 \mathrm{GPa}$, respectively. 


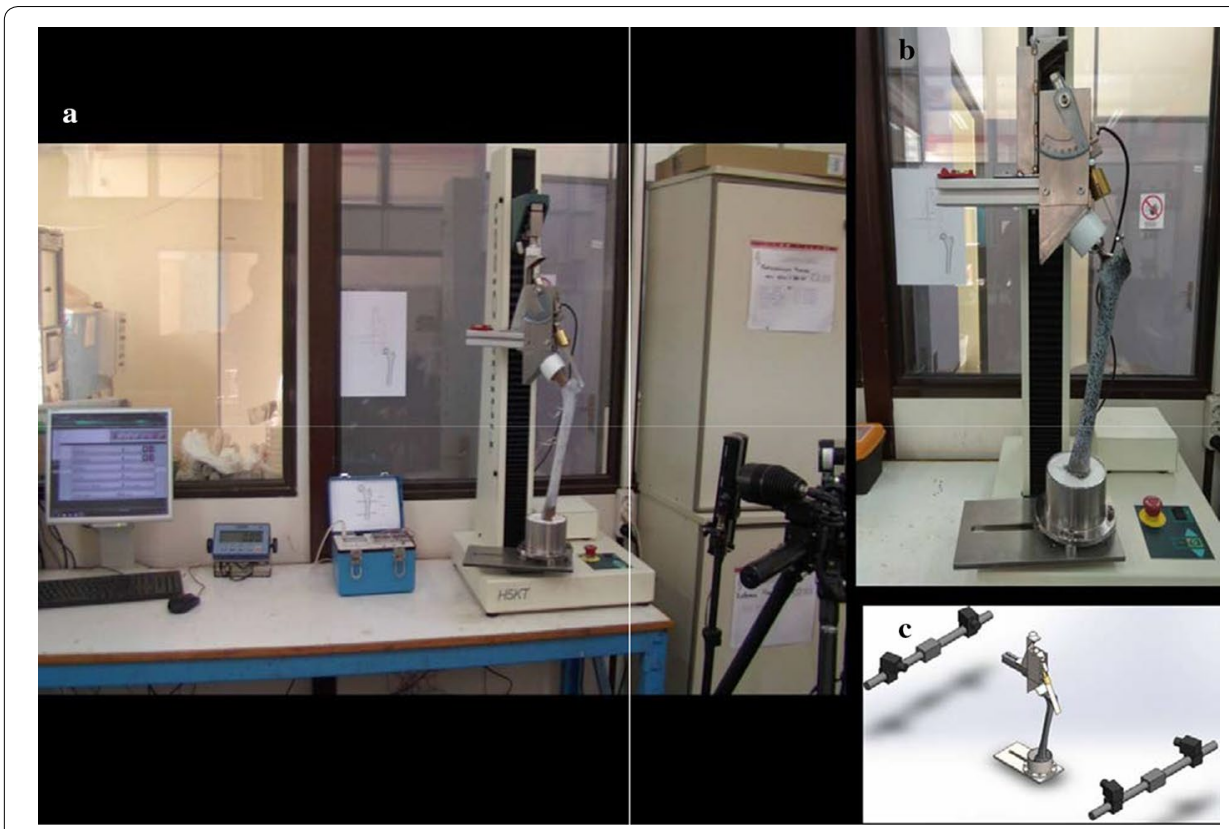

Fig. 5 a Mechanical test setup; $\mathbf{b}$ detailed view of the experimental test setup showing the implanted femur within the customized loading apparatus allowing proximal loading via a compressive joint reaction force at the femoral head paired with a tensile force applied through the abductor plate on the greater trochanter; $\mathbf{c}$ configuration of the data capturing cameras

The Young's modulus of both femoral stems constructed by titanium alloy (Ti6Al4V) was set as $110 \mathrm{GPa}$ and the Poisson's ratio for all materials was set as 0.3 . Fully bonded contact conditions were used between all the components of the tested construct.

For verification purposes, the FE model of the non-implanted femur was validated against the mechanical tests on intact bones. The modeled implanted femurs were used thereafter to calculate strains at the medial and lateral femoral surface in order to identify highly stressed areas. These strain predictions were compared with those developed during mechanical testing of the two implanted stems for validation.

\section{Statistical analysis}

For statistical analysis, two lines have been defined on the same part of each femur; one at the medial surface of the bone and one at the lateral surface. The position and direction of the comparison lines was based on well defined bony landmarks, the anatomical femoral axis and geometrical length measurements. These data were used to find comparable point coordinates in the DIC vs DIC or DIC vs FE corresponding fields (Fig. 6a, b). Key equal zones of interest within each of the two views (medial and lateral) were selected at 2-cm increments along these lines for quantitative strain comparison between experimental groups. Each line was divided in seven equal sections, designated as M1-M7 in medial side and L1-L7 in lateral side (Fig. 6c, d). Statistical analysis was performed utilizing Statistical Package for Social Sciences (SPSS) software (IBM SPSS Statistics version 25). Descriptive analysis was carried out for the intact and implanted femurs, at first globally along the medial and lateral femoral line and then for each key zone of interest, providing standard statistical parameters and the regression curves of strains. Modeling strain error as having 


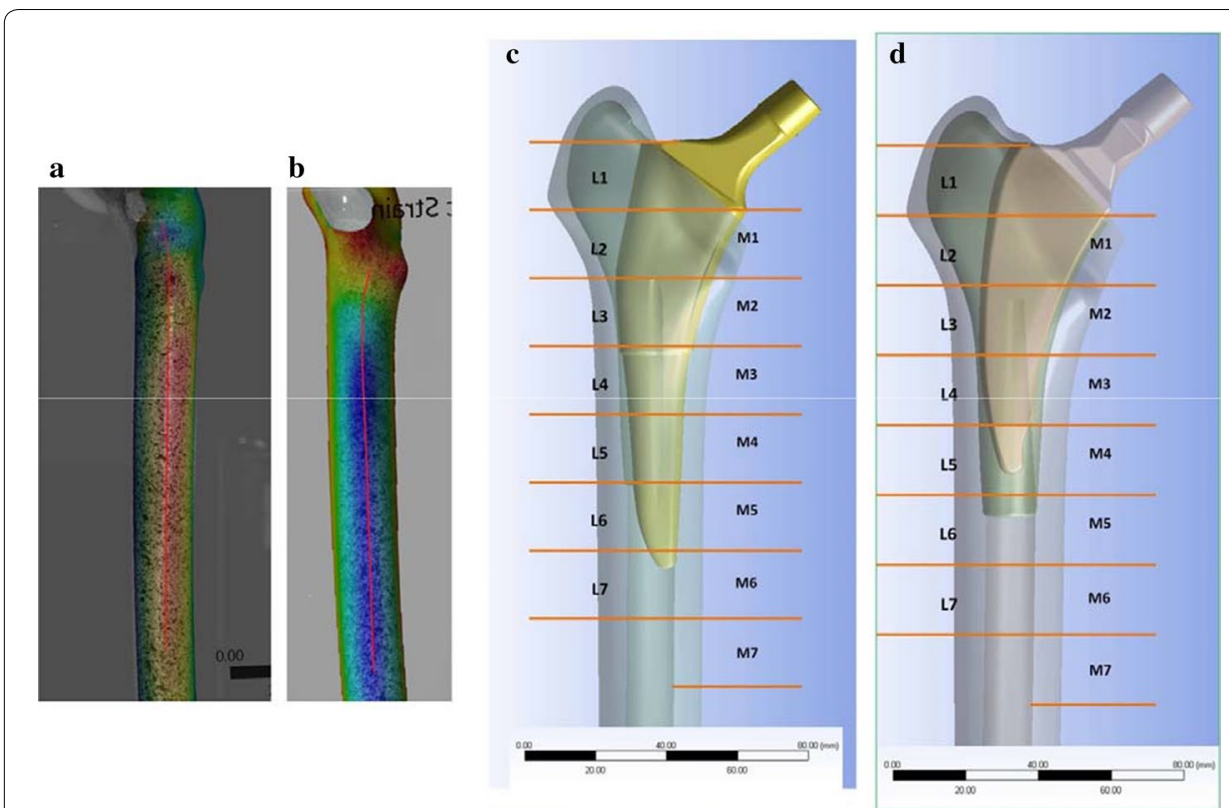

Fig. 6 Comparison lines depicted on the DIC prepared surfaces, superimposed by their corresponding FE fields: a lateral surface; $\mathbf{b}$ medial surface. Key zones of interest at 2-cm increments along the long axis of the femur within each of the two fields of view; $\mathbf{c}$ Trilock BPS stem; d Minima S stem

a normal distribution was tested using Shapiro-Wilk test. The hypothesis of normality was rejected in 35 of the 72 cases at significance level of 5\%. For this reason, a non-parametric Mann-Whitney $U$ test with confidence level 95\% $(a=0.05)$ was used to determine the influence of stem design on strain response at each individual key zone of interest. The $p$ value obtained for each section corresponded to the likelihood that the difference in the mean principal strain for the implanted femur compared to that of the intact femur was due to chance. A $p$-value $<0.05$ was deemed to give rejection with the preset statistical significance. Prior to the FE model validation, the corresponding fields of the DIC vs FE under the same loading were registered together in the ARAMIS environment. Nevertheless, following registration, the comparison points did not have identical locations. For this reason, polynomial of 4th degree approximations of DIC strain data were performed to overcome the exact measurement point mismatch between the two methods. Using the polynomial approximations, reported to the range of points $x$ of the non-implanted FE model, we were able to perform linear correlation analyses for each separate case (intact bone, implanted bones with Minima S and Trilock BPS stem) and field of view (lateral and medial). The linear regression coefficient (slope and intercept) and the coefficient of determination $\left(R^{2}\right)$ were calculated for each analysis with $95 \%$ confidence bounds.

\section{Supplementary information}

Supplementary information accompanies this paper at https://doi.org/10.1186/s12938-020-00806-y.

Additional file 1. Superimposition of the implant template-matched radiographs of the intact femurs on those of the implanted femurs. 


\section{Abbreviations}

THA: Total hip arthroplasty; DIC: Digital image correlation; FEA: Finite element analysis; FE: Finite element; BPS: Bone preservation stem; 3D: Three-dimensional; SPSS: Statistical Package for Social Sciences.

\section{Acknowledgements}

The authors gratefully acknowledge research funding by LimaCorporate S.p.A (Villanova di San Daniele, Italy).

\section{Authors' contributions}

PM conceived the study, received research support and was responsible for the management of the study. PM, IT and ID designed the study. IT and ID were responsible for specimen preparation, execution of experimental analysis and data interpretation. ID created the FE models. PhN provided statistical analysis for the study. IT drafted the manuscript. SP, AP, ID and PM edited and revised the manuscript. All authors reviewed and approved the final version of the manuscript. The study is part of the doctoral thesis of IT.

\section{Funding}

This study was funded in part by LimaCorporate S.p.A. The study was planned, conducted and analyzed independently. The funders had no role in study design, data collection and analysis, interpretation of data, preparation of the manuscript or decision to publish.

\section{Availability of data and materials}

The datasets used and analyzed during the current study are available from the corresponding author on reasonable request.

\section{Ethics approval and consent to participate}

Not applicable.

\section{Consent for publication}

Not applicable.

\section{Competing interests}

This study received research support from the company LimaCorporate S.p.A (Villanova di San Daniele, Italy), which manufactures the Minima S implant. Donation of the femoral implants for testing purposes was supported by LimaCorporate S.p.A, Italy and DePuy Orthopaedics Inc. Warsaw, USA. All authors declare that there exists no further conflict of interest.

\section{Author details}

${ }^{1}$ Orthopaedic Department, University Hospital of Patras, Papanikolaou 1, Rio-Patra, 26504 Patras, Greece. ${ }^{2}$ Laboratory of Technology and Strength of Materials, Department of Mechanical Engineering and Aeronautics, University of Patras, Patras, Greece. ${ }^{3}$ Department of Computer Engineering \& Informatics, University of Patras, Patras, Greece.

Received: 21 April 2020 Accepted: 4 August 2020

Published online: 19 August 2020

\section{References}

1. Kim YH. Long-term results of the cementless porous-coated anatomic total hip prosthesis. J Bone Joint Surg Br. 2005;87(5):623-7. https://doi.org/10.1302/0301-620X.87B5.15554.

2. Lombardi AV, Berend KR, Mallory TH. Hydroxyapatite-coated titanium porous plasma spray tapered stem: experience at 15 to 18 years. Clin Orthop Relat Res. 2006;453:81-5. https://doi.org/10.1097/01.blo.0000238872.01767.09.

3. Marshall AD, Mokris JG, Reitman RD, Dandar A, Mauerhan DR. Cementless titanium tapered-wedge femoral stem: 10- to 15-year follow-up. J Arthroplasty. 2004;19(5):546-52. https://doi.org/10.1016/j.arth.2004.01.006.

4. McLaughlin JR, Lee KR. Total hip arthroplasty with an uncemented tapered femoral component. J Bone Joint Surg Am. 2008;90(6):1290-6. https://doi.org/10.2106/JBJS.G.00771.

5. Burt CF, Garvin KL, Otterberg ET, Jardon OM. A femoral component inserted without cement in total hip arthroplasty: a study of the Tri-Lock component with an average ten-year duration of follow- up. J Bone Joint Surg Am. 1998;80(7):952-60. https://doi.org/10.2106/00004623-199807000-00003.

6. Capello WN, D’Antonio JA, Jaffe WL, Geesink RG, Manley MT, Feinberg JR. Hydroxyapatite-coated femoral components: 15-Year minimum followup. Clin Orthop Relat Res. 2006;453:75-80. https://doi.org/10.1097/01.blo.00002 46534.44629.b2

7. Meding JB, Galley MR, Ritter MA. High survival of uncemented proximally porous-coated titanium alloy femoral stems in osteoporotic bone. Clin Orthop Relat Res. 2010;468(2):441-7. https://doi.org/10.1007/s11999-009-1035-z.

8. Meding JB, Keating EM, Ritter MA, Faris PM, Berend ME. Minimum ten-year follow-up of a straight-stemmed, plasmasprayed, titanium-alloy, uncemented femoral component in primary total hip arthroplasty. J Bone Joint Surg Am. 2004;86(1):92-7. https://doi.org/10.2106/00004623-200401000-00014.

9. Schmidutz F, Grote S, Pietschmann M, Weber P, Mazoochian F, Fottner A, et al. Sports activity after short-stem hip arthroplasty. Am J Sports Med. 2012;40(2):425-32. https://doi.org/10.1177/0363546511424386.

10. Nho SJ, Kymes SM, Callaghan JJ, Felson DT. The burden of hip osteoarthritis in the United States: epidemiologic and economic considerations. J Am Acad Orthop Surg. 2013;21(Suppl 1):1-6. https://doi.org/10.5435/JAAOS-21-07-S1.

11. Eingartner C. Current trends in total hip arthroplasty. Ortop Traumatol Rehabil. 2007;9(1):8-14.

12. Kerner J, Huiskes R, van Lenthe G, Weinans H, van Rietbergen B, Engh C, et al. Correlation between pre-operative periprosthetic bone density and post-operative bone loss in THA can be explained by strain-adaptive remodelling. J Biomech. 1999;32(7):695-703. https://doi.org/10.1016/s0021-9290(99)00041-x. 
13. Nishii T, Sugano N, Masuhara K, Shibuya T, Ochi T, Tamura S. Longitudinal evaluation of time related bone remodeling after cementless total hip arthroplasty. Clin Orthop Relat Res. 1997;339:121-31. https://doi.org/10.1097/00003 086-199706000-00017.

14. Engh CA, Bobyn JD, Glassman AH. Porous-coated hip replacement. The factors governing bone ingrowth, stress shielding, and clinical results. J Bone Joint Surg Br. 1987;69(1):45-55.

15. Engh CA, Bobyn JD. The influence of stem size and extent of porous coating on femoral bone resorption after primary cementless hip arthroplasty. Clin Orthop Relat Res. 1988;231:7-28.

16. Evola FR, Evola G, Graceffa A, Sessa A, Pavone V, Costarella L, et al. Performance of the CLS Spotorno uncemented stem in the third decade after implantation. Bone Joint J. 2014;96-B(4):455-61. https://doi.org/10.1302/0301620x.96b4.32607.

17. Engh CA Jr, Young AM, Engh CA Sr, Hopper RH Jr. Clinical consequences of stress shielding after porous-coated total hip arthroplasty. Clin Orthop Relat Res. 2003;417:157-63. https://doi.org/10.1097/01.blo.0000096825.67494.e3.

18. Karachalios T, Tsatsaronis C, Efraimis G, Papadelis P, Lyritis G, Diakoumopoulos $G$. The long-term clinical relevance of calcar atrophy caused by stress shielding in total hip arthroplasty: a 10-year, prospective, randomized study. J Arthroplasty. 2004;19(4):469-75. https://doi.org/10.1016/j.arth.2003.12.081.

19. Glassman AH, Bobyn JD, Tanzer M. New femoral designs: do they influence stress shielding? Clin Orthop Relat Res. 2006;453:64-74. https://doi.org/10.1097/01.blo.0000246541.41951.20.

20. Bugbee WD, Culpepper WJ, Engh CA, Engh CA. Long-term clinical consequences of stress-shielding after total hip arthroplasty without cement. J Bone Joint Surg Am. 1997;79(7):1007-12. https://doi.org/10.2106/00004623-19970 7000-00006.

21. Huo S-C, Wang F, Dong L-J, Wei W, Zeng J-Q, Huang H-X, et al. Short-stem prostheses in primary total hip arthroplasty: a meta-analysis of randomized controlled trials. Medicine (Baltimore). 2016;95(43):e5215. https://doi. org/10.1097/MD.0000000000005215.

22. Castelli CC, Rizzi L. Short stems in total hip replacement: current status and future. Hip Int. 2014;24(Suppl 10):S25-8. https://doi.org/10.5301/hipint.5000169.

23. Gabarre S, Herrera A, Ibarz E, Mateo J, Gil-Albarova J, Gracia L. Comparative analysis of the biomechanical behaviour of two cementless short stems for hip replacement: linea anatomic and minihip. PLoS ONE. 2016;11(7):e0158411. https://doi.org/10.1371/journal.pone.0158411.

24. Small SR, Hensley SE, Cook PL, Stevens RA, Rogge RD, Meding JB, et al. Characterization of femoral component initial stability and cortical strain in a reduced stem-length design. J Arthroplasty. 2017;32(2):601-9. https://doi. org/10.1016/j.arth.2016.07.033.

25. Otani T, Whiteside LA, White SE. Strain distribution in the proximal femur with flexible composite and metallic femoral components under axial and torsional loads. J Biomed Mater Res. 1993;27(5):575-85. https://doi.org/10.1002/ jbm.820270504.

26. Østbyhaug PO, Klaksvik J, Romundstad P, Aamodt A. An in vitro study of the strain distribution in human femora with anatomical and customised femoral stems. J Bone Joint Surg Br. 2009;91 (5):676-82. https://doi. org/10.1302/0301-620X.91B5.21749.

27. Maistrelli GL, Fornasier V, Binnington A, McKenzie K, Sessa V, Harrington I. Effect of stem modulus in a total hip arthroplasty model. J Bone Joint Surg Br. 1991;73(1):43-6.

28. Decking R, PuhI W, Simon U, Claes LE. Changes in strain distribution of loaded proximal femora caused by different types of cementless femoral stems. Clin Biomech (Bristol, Avon). 2006;21(5):495-501. https://doi.org/10.1016/j.clinb iomech.2005.12.011.

29. Kuiper JH, Huiskes R. Mathematical optimization of elastic properties: application to cementless hip stem design. J Biomech Eng. 1997:119(2):166-74. https://doi.org/10.1115/1.2796076.

30. Morscher EW, Dick W. Cementless fixation of "isoelastic" hip endoprostheses manufactured from plastic materials. Clin Orthop Relat Res. 1983;176:77-87.

31. Tayton E, Evans $S$, O'Doherty D. Mapping the strain distribution on the proximal femur with titanium and flexible-stemmed implants using digital image correlation. J Bone Joint Surg Br. 2010;92(8):1176-81. https://doi. org/10.1302/0301-620X.92B8.23553.

32. Boyle C, Kim IY. Comparison of different hip prosthesis shapes considering micro-level bone remodeling and stressshielding criteria using three-dimensional design space topology optimization. J Biomech. 2011;44(9):1722-8. https ://doi.org/10.1016/j.jbiomech.2011.03.038.

33. Ridzwan MIZ, Shuib S, Hassan AY, Shokri AA, Ibrahim MNM. Optimization in implant topology to reduce stress shielding problem. J Appl Sci. 2006;6(13):2768-73.

34. Gross $\mathrm{S}$, Abel E. A finite element analysis of hollow stemmed hip prostheses as a means of reducing stress shielding of the femur. J Biomech. 2001;34(8):995-1003. https://doi.org/10.1016/s0021-9290(01)00072-0.

35. Joshi MG, Advani SG, Miller F, Santare MH. Analysis of a femoral hip prosthesis designed to reduce stress shielding. J Biomech. 2000;33(12):1655-62. https://doi.org/10.1016/s0021-9290(00)00110-x.

36. van Rietbergen B, Huiskes R. Load transfer and stress shielding of the hydroxyapatite-ABG hip: a study of stem length and proximal fixation. J Arthroplasty. 2001;16(8 Suppl 1):55-63. https://doi.org/10.1054/arth.2001.28369.

37. Jetté B, Brailovski V, Simoneau C, Dumas M, Terriault P. Development and in vitro validation of a simplified numerical model for the design of a biomimetic femoral stem. J Mech Behav Biomed Mater. 2018;77:539-50. https://doi. org/10.1016/j.jmbbm.2017.10.019.

38. Cilla M, Checa S, Duda GN. Strain shielding inspired re-design of proximal femoral stems for total hip arthroplasty. J Orthop Res. 2017;35(11):2534-44. https://doi.org/10.1002/jor.23540.

39. Gómez-García F, Fernández-Fairen M, Espinosa-Mendoza RL. A proposal for the study of cementless short-stem hip prostheses. Acta Ortop Mex. 2016;30(4):204-15.

40. Viceconti M, Affatato S, Baleani M, Bordini B, Cristofolini L, Taddei F. Pre-clinical validation of joint prostheses: a systematic approach. J Mech Behav Biomed Mater. 2009;2(1):120-7. https://doi.org/10.1016/j.jmbbm.2008.02.005. 
41. Cristofolini L, Schileo E, Juszczyk M, Taddei F, Martelli S, Viceconti M. Mechanical testing of bones: the positive synergy of finite-element models and in vitro experiments. Philos Trans A Math Phys Eng Sci. 1920;2010(368):2725-63. https://doi.org/10.1098/rsta.2010.0046.

42. Bieger $R$, Ignatius $A$, Decking $R$, Claes $L$, Reichel $H$, Dürselen $L$. Primary stability and strain distribution of cementless hip stems as a function of implant design. Clin Biomech (Bristol, Avon). 2012;27(2):158-64. https://doi.org/10.1016/j. clinbiomech.2011.08.004.

43. Bieger $R$, Ignatius $A$, Reichel $H$, Dürselen $L$. Biomechanics of a short stem: in vitro primary stability and stress shielding of a conservative cementless hip stem. J Orthop Res. 2013;31 (8):1180-6. https://doi.org/10.1002/jor.22349.

44. Cook GE, Samiezadeh S, Morison Z, Aziz MSR, Bougherara H, Zdero R, et al. Biomechanical optimization of the angle and position for surgical implantation of a straight short stem hip implant. Med Eng Phys. 2017;39:23-30. https:// doi.org/10.1016/j.medengphy.2016.10.002.

45. Gronewold J, Berner S, Olender G, Hurschler C, Windhagen H, Von Lewinski G, et al. Changes in strain patterns after implantation of a short stem with metaphyseal anchorage compared to a standard stem: an experimental study in synthetic bone. Orthop Rev (Pavia). 2014;6(1):5211. https://doi.org/10.4081/or.2014.5211.

46. Zhou XM, Walker PS, Robertson DD. Effect of press-fit femoral stems on strains in the femur. J Arthroplasty. 1990;5(1):71-82. https://doi.org/10.1016/s0883-5403(06)80013-6.

47. Wuh H, Jones L, Hungerford D. Strain Analysis of the Proximal Femur After Total Hip Replacement. In: Jack E. Lemons editor. Quantitative characterization and performance of porous implants for hard tissue applications. ASTM special technical publication 953; 1987. p. 249-263.

48. Huiskes R, Weinans H, Dalstra M. Adaptive bone remodeling and biomechanical design considerations for noncemented total hip arthroplasty. Orthopedics. 1989;12(9):1255-67.

49. Huiskes $R$, Weinans $H$, van Rietbergen $B$. The relationship between stress shielding and bone resorption around total hip stems and the effects of flexible materials. Clin Orthop Relat Res. 1992;274:124-34.

50. Katz Y, Lubovsky O, Yosibash Z. Patient-specific finite element analysis of femurs with cemented hip implants. Clin Biomech (Bristol, Avon). 2018;58:74-89. https://doi.org/10.1016/j.clinbiomech.2018.06.012.

51. Roberts VL. Strain-gage techniques in biomechanics. Exp Mech. 1966;6(3):19A-22A.

52. Hensley S, Christensen M, Small S, Archer D, Lakes E, Rogge R. Digital image correlation techniques for strain measurement in a variety of biomechanical test models. Acta Bioeng Biomech. 2017;19(3):187-95.

53. Väänänen SP, Amin Yavari S, Weinans H, Zadpoor AA, Jurvelin JS, Isaksson H. Repeatability of digital image correlation for measurement of surface strains in composite long bones. J Biomech. 2013;46(11):1928-32. https://doi. org/10.1016/j.jbiomech.2013.05.021.

54. Dickinson AS, Taylor AC, Ozturk H, Browne M. Experimental validation of a finite element model of the proximal femur using digital image correlation and a composite bone model. J Biomech Eng. 2011;133(1):014504. https://doi. org/10.1115/1.4003129.

55. Ghosh R, Gupta S, Dickinson A, Browne M. Experimental validation of finite element models of intact and implanted composite hemipelvises using digital image correlation. J Biomech Eng. 2012;134(8):081003. https://doi. org/10.1115/1.4007173.

56. Grassi L, Väänänen SP, Amin Yavari S, Weinans H, Jurvelin JS, Zadpoor AA, et al. Experimental validation of finite element model for proximal composite femur using optical measurements. J Mech Behav Biomed Mater. 2013;21:86-94. https://doi.org/10.1016/j.jmbbm.2013.02.006.

57. Grassi L, Väänänen SP, Ristinmaa M, Jurvelin JS, Isaksson H. How accurately can subject-specific finite element models predict strains and strength of human femora? Investigation using full-field measurements. J Biomech. 2016:49(5):802-6. https://doi.org/10.1016/j.jbiomech.2016.02.032.

58. Gustafson HM, Cripton PA, Ferguson SJ, Helgason B. Comparison of specimen-specific vertebral body finite element models with experimental digital image correlation measurements. J Mech Behav Biomed Mater. 2017;65:801-7. https://doi.org/10.1016/j.jmbbm.2016.10.002.

59. Taddei F, Cristofolini L, Martelli S, Gill HS, Viceconti M. Subject-specific finite element models of long bones: an in vitro evaluation of the overall accuracy. J Biomech. 2006;39(13):2457-67. https://doi.org/10.1016/j.jbiom ech.2005.07.018.

60. Small SR, Rogge RD, Malinzak RA, Reyes EM, Cook PL, Farley KA, et al. Micromotion at the tibial plateau in primary and revision total knee arthroplasty: fixed versus rotating platform designs. Bone Joint Res. 2016;5(4):1229. https://doi.org/10.1302/2046-3758.54.2000481.

61. Ike H, Inaba Y, Kobayashi N, Hirata Y, Yukizawa Y, Aoki C, et al. Comparison between mechanical stress and bone mineral density in the femur after total hip arthroplasty by using subject-specific finite element analyses. Comput Methods Biomech Biomed Engin. 2015;18(10):1056-65. https://doi.org/10.1080/10255842.2013.869320.

62. Baharuddin MY, Salleh S-H, Zulkifly AH, Lee MH, Noor AM, Harris AAR, et al. Design process of cementless femoral stem using a nonlinear three dimensional finite element analysis. BMC Musculoskelet Disord. 2014;15:30. https://doi.org/10.1186/1471-2474-15-3071-2474-15-30.

63. Arno S, Fetto J, Nguyen NQ, Kinariwala N, Takemoto R, Oh C, et al. Evaluation of femoral strains with cementless proximal-fill femoral implants of varied stem length. Clin Biomech (Bristol, Avon). 2012;27(7):680-5. https://doi. org/10.1016/j.clinbiomech.2012.03.006.

64. Østbyhaug PO, Klaksvik J, Romundstad P, Aamodt A. Shortening of an anatomical stem, how short is short enough? An in vitro study of load transfer and primary stability. Proc Inst Mech Eng H. 2013;227(5):481-9. https ://doi.org/10.1177/0954411912471779.

65. Ong KL, Day JS, Manley MT, Kurtz SM, Geesink R. Biomechanical comparison of 2 proximally coated femoral stems: effects of stem length and surface finish. J Arthroplasty. 2009;24(5):819-24. https://doi.org/10.1016/j. arth.2008.09.012.

66. Umeda N, Saito M, Sugano N, Ohzono K, Nishii T, Sakai T, et al. Correlation between femoral neck version and strain on the femur after insertion of femoral prosthesis. J Orthop Sci. 2003;8(3):381-6. https://doi.org/10.1007/ s10776-002-0635-2. 
67. Lerch M, von der Haar-Tran A, Windhagen H, Behrens BA, Wefstaedt P, Stukenborg-Colsman CM. Bone remodelling around the Metha short stem in total hip arthroplasty: a prospective dual-energy X-ray absorptiometry study. Int Orthop. 2012;36(3):533-8. https://doi.org/10.1007/s00264-011-1361-0.

68. Papini M, Zdero R, Schemitsch EH, Zalzal P. The biomechanics of human femurs in axial and torsional loading: comparison of finite element analysis, human cadaveric femurs, and synthetic femurs. J Biomech Eng. 2007;129(1):12-9. https://doi.org/10.1115/1.2401178.

69. Cristofolini L, Viceconti M. Mechanical validation of whole bone composite tibia models. J Biomech. 2000;33(3):279-88. https://doi.org/10.1016/s0021-9290(99)00186-4.

70. Cristofolini L, Viceconti M, Cappello A, Toni A. Mechanical validation of whole bone composite femur models. J Biomech. 1996;29(4):525-35. https://doi.org/10.1016/0021-9290(95)00084-4.

71. Heiner AD. Structural properties of fourth-generation composite femurs and tibias. J Biomech. 2008;41(15):3282-4. https://doi.org/10.1016/j.jbiomech.2008.08.013.

72. Østbyhaug PO, Klaksvik J, Romundstad P, Aamodt A. Primary stability of custom and anatomical uncemented femoral stems: a method for three-dimensional in vitro measurement of implant stability. Clin Biomech (Bristol, Avon). 2010;25(4):318-24. https://doi.org/10.1016/j.clinbiomech.2009.12.012.

73. Cristofolini L, Viceconti M, Toni A, Giunti A. Influence of thigh muscles on the axial strains in a proximal femur during early stance in gait. J Biomech. 1995;28(5):617-24. https://doi.org/10.1016/0021-9290(94)00106-e.

74. Cristofolini L. A critical analysis of stress shielding evaluation of hip prostheses. Crit Rev Biomed Eng. 1997;25(45):409-83. https://doi.org/10.1615/critrevbiomedeng.v25.14-5.30.

75. McLeish RD, Charnley J. Abduction forces in the one-legged stance. J Biomech. 1970;3(2):191-209. https://doi. org/10.1016/0021-9290(70)90006-0.

76. Tatani I, Panagopoulos A, Diamantakos I, Sakellaropoulos G, Pantelakis S, Megas P. Comparison of two metaphyseal-fitting (short) femoral stems in primary total hip arthroplasty: study protocol for a prospective randomized clinical trial with additional biomechanical testing and finite element analysis. Trials. 2019;20(1):359. https://doi. org/10.1186/s13063-019-3445-X.

77. Waide V, Cristofolini L, Stolk J, Verdonschot N, Toni A. Experimental investigation of bone remodelling using composite femurs. Clin Biomech (Bristol, Avon). 2003;18(6):523-36. https://doi.org/10.1016/s0268 $-0033(03) 00072-x$.

78. Fottner A, Schmid M, Birkenmaier C, Mazoochian F, Plitz W, Volkmar J. Biomechanical evaluation of two types of short-stemmed hip prostheses compared to the trust plate prosthesis by three-dimensional measurement of micromotions. Clin Biomech (Bristol, Avon). 2009;24(5):429-34. https://doi.org/10.1016/j.clinbiomec h.2009.02.007.

79. Ganapathi M, Evans S, Roberts P. Strain pattern following surface replacement of the hip. Proc Inst Mech Eng H. 2008;222(1):13-8. https://doi.org/10.1243/09544119JEIM322.

80. Hnat WP, Conway JS, Malkani AL, Yakkanti MR, Voor MJ. The effect of modular tapered fluted stems on proximal stress shielding in the human femur. J Arthroplasty. 2009;24(6):957-62. https://doi.org/10.1016/j.arth.2008.07.013.

81. Tai CL, Lee MS, Chen WP, Hsieh PH, Lee PCSC. Biomechanical comparison of newly designed stemless prosthesis and conventional hip prosthesis-an experimental study. Biomed Mater Eng. 2005;15(3):239-49.

82. Ruff CB, Hayes WC. Cross-sectional geometry of Pecos Pueblo femora and tibiae-a biomechanical investigation: I. Method and general patterns of variation. Am J Phys Anthropol. 1983;60(3):359-81. https://doi.org/10.1002/ ajpa.1330600308.

83. Cristofolini L, Viceconti M. Towards the standardization of in vitro load transfer investigations of hip prostheses. J Strain Anal Eng Des. 1999;34(1):1-15.

84. Bergmann G, Graichen F, Rohlmann A. Hip joint loading during walking and running, measured in two patients. J Biomech. 1993;26(8):969-90. https://doi.org/10.1016/0021-9290(93)90058-m.

85. Bergmann G, Kniggendorf H, Graichen F, Rohlmann A. Influence of shoes and heel strike on the loading of the hip joint. J Biomech. 1995;28(7):817-27. https://doi.org/10.1016/0021-9290(94)00129-r.

\section{Publisher's Note}

Springer Nature remains neutral with regard to jurisdictional claims in published maps and institutional affiliations.

Ready to submit your research? Choose BMC and benefit from:

- fast, convenient online submission

- thorough peer review by experienced researchers in your field

- rapid publication on acceptance

- support for research data, including large and complex data types

- gold Open Access which fosters wider collaboration and increased citations

- maximum visibility for your research: over $100 \mathrm{M}$ website views per year

At BMC, research is always in progress.

Learn more biomedcentral.com/submissions 